Original Research Paper

\title{
Investigation of Shear Lag Factor in Long Structures with Pipeline System in Tubes under Wind Load
}

\author{
${ }^{1}$ Reza Salehi and ${ }^{2}$ Alireza Khaloo \\ ${ }^{1}$ Master Graduated Student, Islamic Azad University, South Branch, Tehran, Iran \\ ${ }^{2}$ Professor of Structural Engineering, Sharif University of Technology, Tehran, Iran
}

Article history

Received: 18-04-2018

Revised: 20-04-2018

Accepted: 19-05-2018

Corresponding Author:

Reza Salehi

Master Graduated Student,

Islamic Azad University, South

Branch, Tehran, Iran

Email: salehi.reza14@yahoo.com

\section{Introduction}

The construction of towers and high-rise buildings has long been interesting to structural engineers. Execution of high structures initially has been aimed at protecting, defending and then practical and applied aspects. The development of high-rise buildings began in the 80's and nineteenth century with commercial and residential uses and now some of them are as permanent symbols in the world. Execution of high-rise buildings, was a major problem for structural and geotechnical engineers, especially if these projects are in earthquake- areas or risky substrates such as lowdensity and loose soils (Smith and Coull, 1991). In high structures, rigidity and stability are more important than resistance (the main characteristic of short structures). When the height of the building increases, wind and earthquakes will dominate the building and its importance will increase throughout the robust system.
In these structures, the effect of higher buildings in the design of the structure is significant. Systems resistant to lateral loads that are widely used in structures include rigid frames, braced frames, truss braces and framed tubes (Kheyroddin and Aramesh, 2013; Bagheri, 2012; Tohidi, 1996). In the case of a pipe system, the effect of pipe camping on the improvement of the peripheral behavior of a cone structure has been confirmed in previous studies (Moghaddasi and Keramati, 2007; Moghadasi, 2009). This system was first used by Fazloor and Milestone to build high-rise buildings. In this system, the exterior walls of the building consist of a network of beams and columns close to each other, which are connected with rigid connections and act against side loads such as bending a cantilever beam with hole. As a result, the lateral forces of the side opposite to the lateral forces are shortened and the longitudinal lateral sidewalls are extended (Moghaddasi and Keramati, 2007; Khan, 
1972). Fallahi et al. (2018) did numerical study on RC frame under cyclic loading condition as a lateral force using displacement control system to take reaction force of whole system in order to investigate the effect of RC wall with or without partitioning. Moreover, in a pipe design, such as exterior walls, the lateral load is more likely to be removed, the diagonal braces or expensive interior shear walls are removed. Tubular structures look like walls with multiple holes. The facade wall hardness can be increased by adding diagonal braces, which create a truss effect. The pipe is too rigid so that it acts as a beam in front of the lateral loads. The external tube can stand all the lateral loads alone, or by adding a kind of internal bracing, the pipe can be further strengthened and hardened, while the mid-column only bear the gravity load (Kheyroddin and Jamshidi, 2008; Kheyroddin and Naderpour, 2011; Paveloni, 2012; Taranath, 1982). Soleimani and Roudsari (2015; Sayyar Roudsari Roudsari et al., 2018; Roudsari et al. 2018) did shear evaluation in different structural elements to find out the effect of different ratio of dimension for RC beams and columns to investigate the shear criteria under extreme loading condition.

\section{Modeling}

The purpose of this study was to evaluate the behavior of high-rise concrete buildings with the pipe system in a pipe grouped under the influence of wind load. For this purpose, a 40 -stories high-rise building is considered using ETABS software. The dimensions of the plan are $30 \times 30$ square meters. The spacing of the columns in the pipe system is $2.5 \mathrm{~m}$ in length. The height of the floors is $3.8 \mathrm{~m}$. Figure 1 shows the plan for the mentioned buildings. Specifications of concrete used in modeling are presented in Table 1. The specifications of the main bars and rods are presented in Table 2.

The dead load of the building floors is 350 and the live load of the floors is $200 \mathrm{~kg} / \mathrm{m}^{2}$, respectively. Also, the distributed loading is $650 \mathrm{~kg} / \mathrm{m}^{2}$ for partition loads. In order to design the elements of the buildings, the ACI 318-11 has been used. The combination of design loads is also regulated by the rules. The lateral load in the design of the wind load is ASCE7-10. The speed which uses for design is $90 \mathrm{~km} / \mathrm{h}$ and the city of Arak is included. In the design of the elements, cracking coefficients have been applied based on standard 2800 fourth. In the modeling of the buildings of the second floor, shear wall system is used. The changes in the sections of the beam and column in all buildings are carried out every 10 floors. The lateral load system of the buildings is also a special concrete moment frame. Figure 1 shows the plan of different building levels and the shape of the two front aspects and three-dimensional aspect of the structure.

Table 1: Mechanical properties of concrete

\begin{tabular}{lllll}
\hline $\begin{array}{l}\text { Mechanical } \\
\text { specification }\end{array}$ & $\begin{array}{l}\text { Pushing resistance } \\
\left(\mathrm{kg} / \mathrm{cm}^{3}\right)\end{array}$ & Poisson's ratio & $\begin{array}{l}\text { Special Weight } \\
\left(\mathrm{kg} / \mathrm{m}^{3}\right)\end{array}$ & $\begin{array}{l}\text { Elasticity } \\
\text { coefficient }\left(\mathrm{kg} / \mathrm{cm}^{2}\right)\end{array}$ \\
\hline Concrete & 350 & 0.2 & 2450 & 302000 \\
\hline
\end{tabular}

Table 2: Mechanical properties of steel

\begin{tabular}{lllll}
\hline $\begin{array}{l}\text { Mechanical } \\
\text { specification }\end{array}$ & $\begin{array}{l}\text { Yield stress } \\
\left(\mathrm{kg} / \mathrm{cm}^{2}\right)\end{array}$ & $\begin{array}{l}\text { Ultimate stress } \\
\left(\mathrm{kg} / \mathrm{cm}^{2}\right)\end{array}$ & $\begin{array}{l}\text { Special Weight } \\
\left(\mathrm{kg} / \mathrm{m}^{3}\right)\end{array}$ & $\begin{array}{l}\text { Elasticity } \\
\text { coefficient }\left(\mathrm{kg} / \mathrm{cm}^{2}\right)\end{array}$ \\
\hline Steel AII & 3000 & 5000 & 7850 & 2060000 \\
Steel AIII & 4000 & 6000 & 7850 & 2060000 \\
\hline
\end{tabular}

Table 3: The sections of the beam and columns of buildings of 40 floors

\begin{tabular}{lllc} 
Number of floors & $\begin{array}{l}\text { Column section } \\
\mathrm{a} \times \mathrm{b}\left(\mathrm{cm}^{2}\right) \text { and }(\mathrm{mm})\end{array}$ & $\begin{array}{l}\text { Surface density of } \\
\text { steel columns (\%) }\end{array}$ & $\begin{array}{l}\text { Cross } \\
\text { section } \mathrm{cm}^{2}\end{array}$ \\
\hline Third floor to tenth & $140 \times 60-56 \mathrm{~d} 32$ & $5.35 \%$ & $140 \times 60$ \\
11 th to 20th floor & $140 \times 55-56 \mathrm{~d} 28$ & $4.47 \%$ & $140 \times 55$ \\
21 st to 30th floor & $140 \times 50-46 \mathrm{~d} 26$ & $3.48 \%$ & $140 \times 50$ \\
31 to $40^{\text {th }}$ floor & & & $1.44 \%$ \\
\hline
\end{tabular}




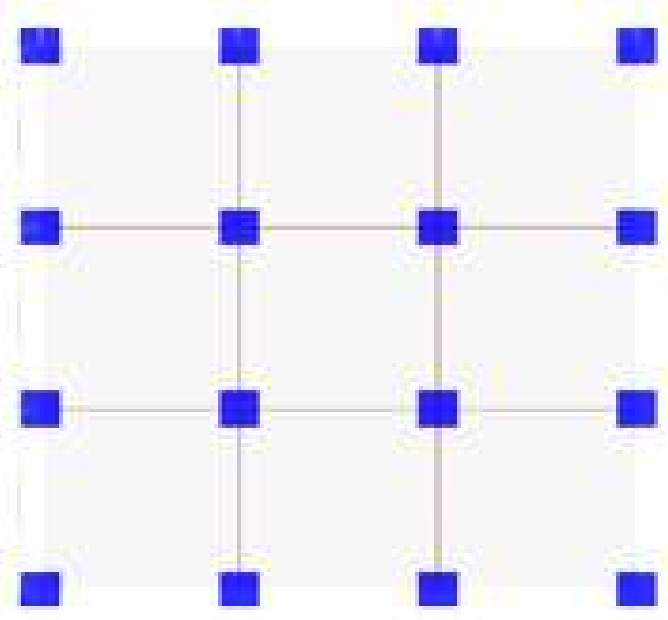

(a)

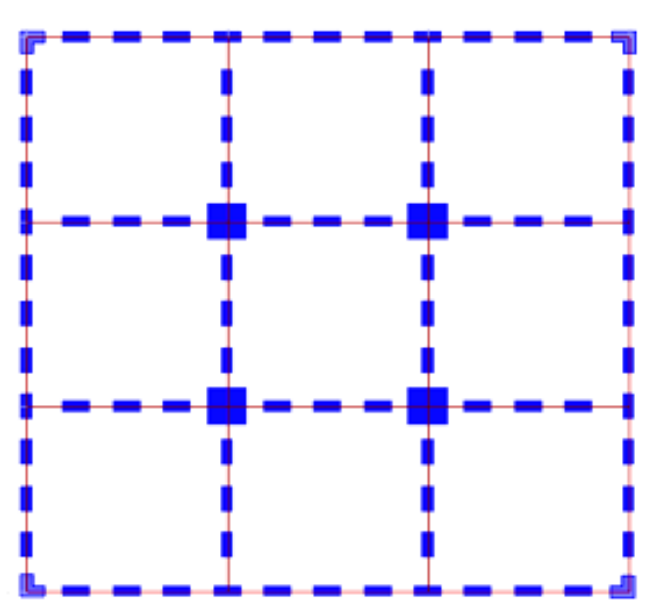

(c)

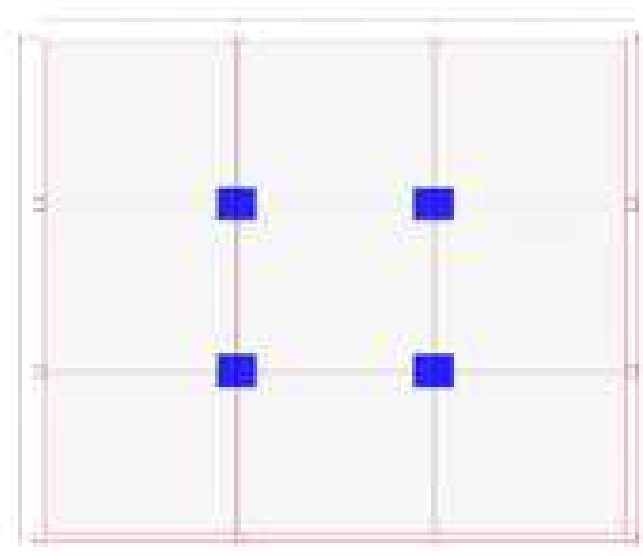

(b)

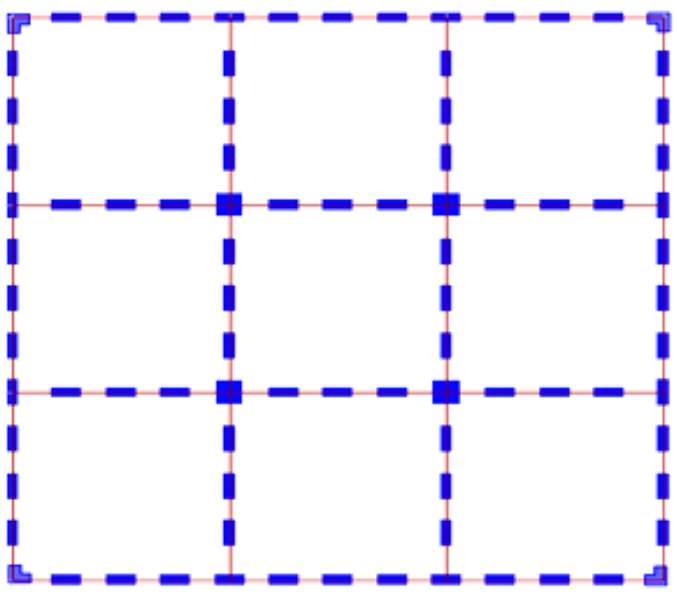

(d)

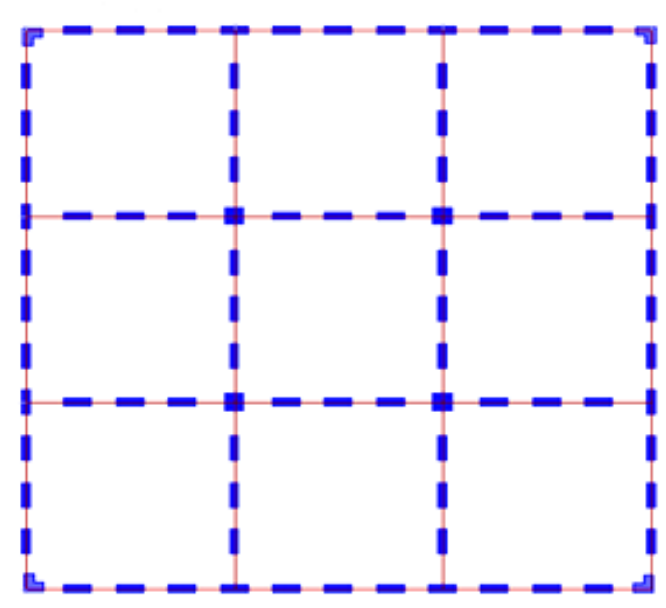

(e)

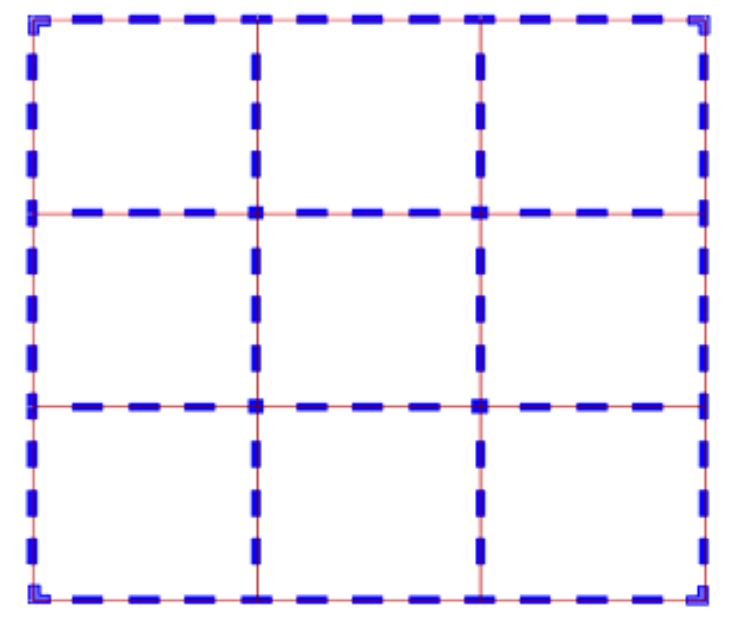

(f)

Fig. 1: Plans for different floors of the building of 40 floors (a) 1st floor (b) 2nd floor (c) 3rd to 10th floor (d) 11th to 20th floor (e) 20rd to 30th floor (f) 31th to 40th floor 

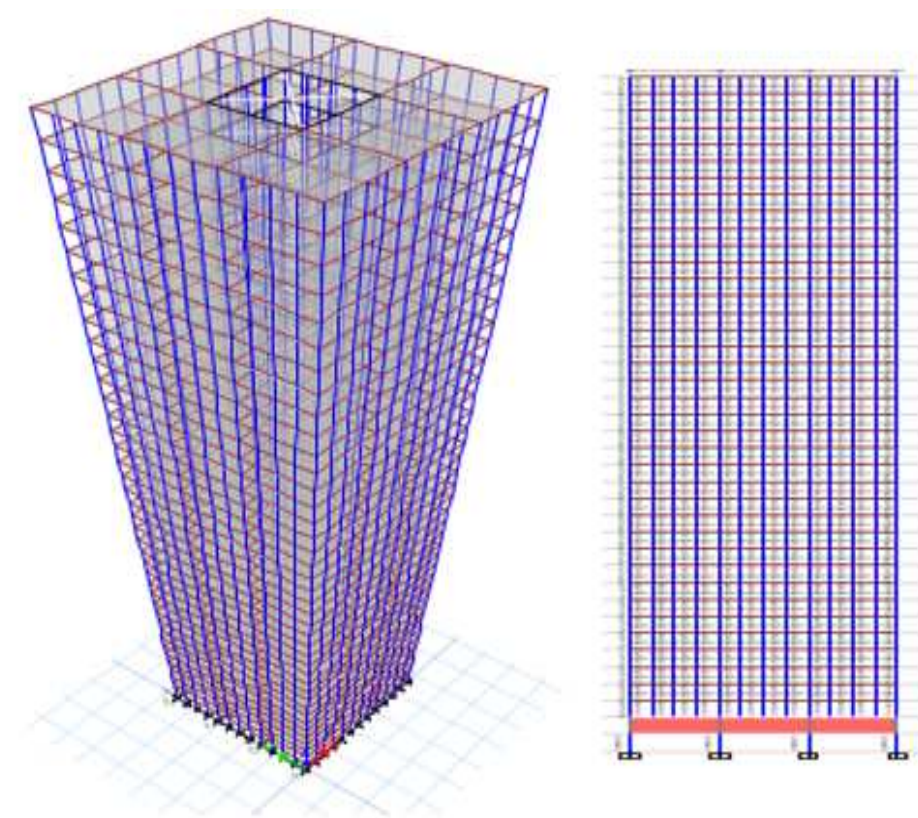

Fig. 2: Front and three-dimensional aspects 40 -story building

The element modeling has been done using frame section module by choosing the rectangular shape of solid section. The cover of the concrete is considered 50 millimeter and in order to optimize the time of modeling, all rebars which are used include 32, 28,26 and 22 millimeters diameter. The section properties are shown in Table 3. Moreover, the same deck is assigned for all floors by defining membrane modeling of the double deck properties as $60 \mathrm{~cm}$ gap for each support and $30 \mathrm{~cm}$ the concrete depth and $5 \mathrm{~cm}$ concrete cover and all of the floors are considered as solid diaphragm. In order to define the loading condition, the static load cases are used by defining dead load, live load, wall load, Earthquake in $\mathrm{X}$ direction (EX), Earthquake in $\mathrm{Y}$ direction (EY) and wind load. The linear static analysis has been used to apply these loading conditions. In order to define the wind load coefficient, the 2800- Iranian Standard (Iranian Code of Practice 2800) is exploited. In addition, in order to define the coefficient number, UBC 97 seismic loading parameters is used by assigning seismic coefficient, time period, importance factor and overs-strength factor of R. The uniform loading is used for live, dead and wall load by choosing uniform surface load and the gravity direction. The distributed line load is also used for assigning the same load for partitions. As the UBC 97 standard is used, the default load combination which can be generated by ETABS 9.7.4 automatically is considered.

It should be noted that, the structure is evaluated under wind loading condition. Therefore, several sets and labels were assigned to the columns which were at the same side of loading conditions. These labels and sets were defined in the different stories to take output of analysis. Also, the axial forces were taken from middle and corner columns using show table toolbox in ETABS software by declaring the wind load and critical load combinations. Then, the outputs were compared to each other.

It should be noted that all the first and second floor columns are $200 \mathrm{~cm}^{2}$. The dimensions of the four pillars of the middle of the third floor up to the tenth square with a length of each side of $200 \mathrm{~cm}$, the floor of the eleventh to twentieth century, the length of the section of these columns is $125 \mathrm{~cm}$ and then every ten floor $25 \mathrm{~cm}$ of their dimensions are reduced. The lateral shear wall of the model on the second floor is also 60 $\mathrm{cm}$ thick and is equivalent to the width of the third floors columns. Fig. 2 shows the three dimensional and front view of the building.

\section{Results and Discussion}

According Fig. 3, the maximum displacement of structure is carried by choosing the wind- load combination which is clear that by increasing the height of the building the displacement is increased. Figure 4 shows the hardness of the building floors, so that as it can be seen, in the lower floor the hardness of structure has significantly increased under wind lading condition. It should be mentioned that by existing of the shear wall in the second floor and due, to the large dimensions of the first-pillar columns, the hardness of this floor is more than the other floors. Figure 5 shows shear load of the structural floors 
under the wind loadwhich by looking at the figure it can be declared that in the higher floors the shear force is lower and by decreasing the number of floor the shear force is increased.

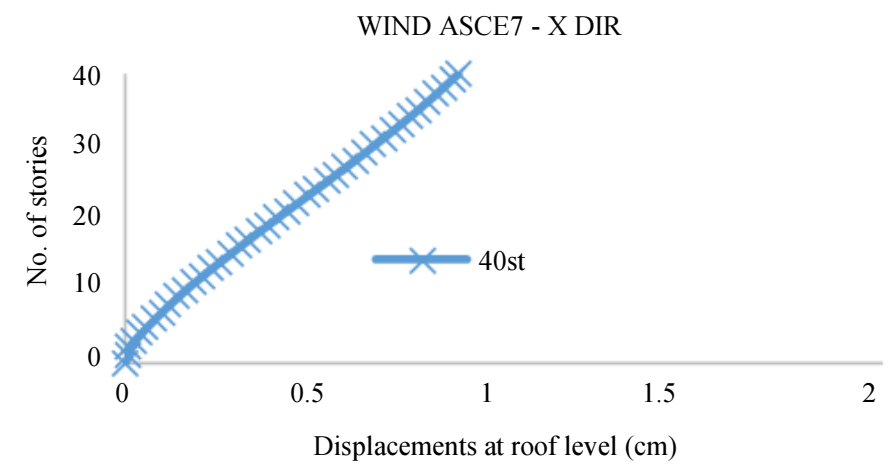

Fig. 3: The displacement of the floors of the 40-storey building under the wind load

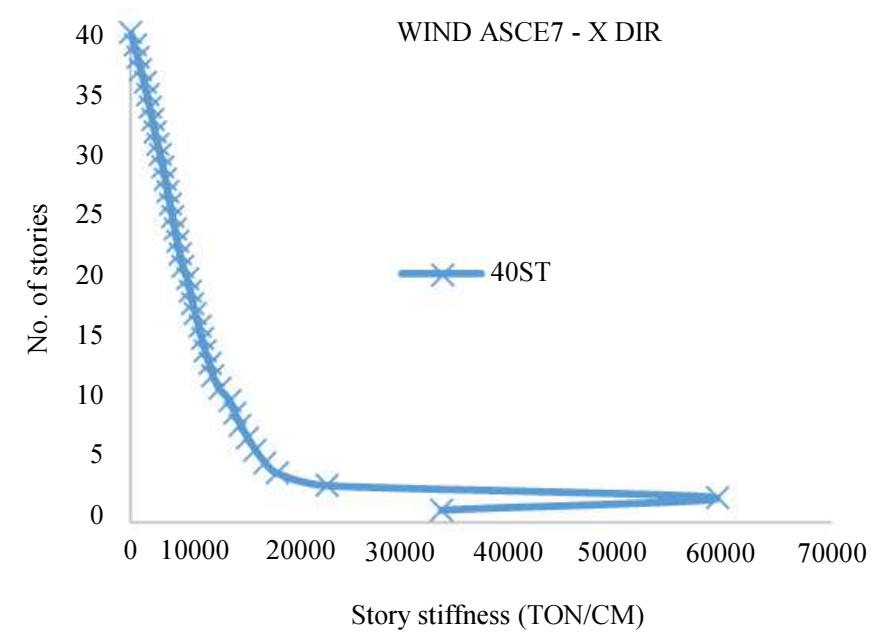

Fig. 4: Hardness of the floors of the building is 40 floors

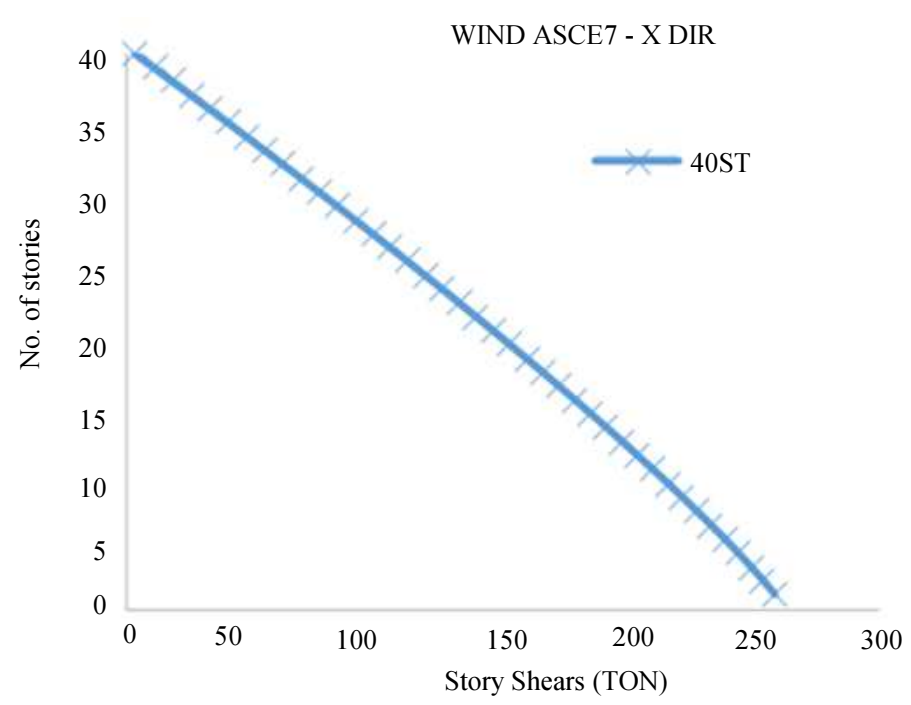

Fig. 5: Shear of floors of the building 40 floors under wind load 


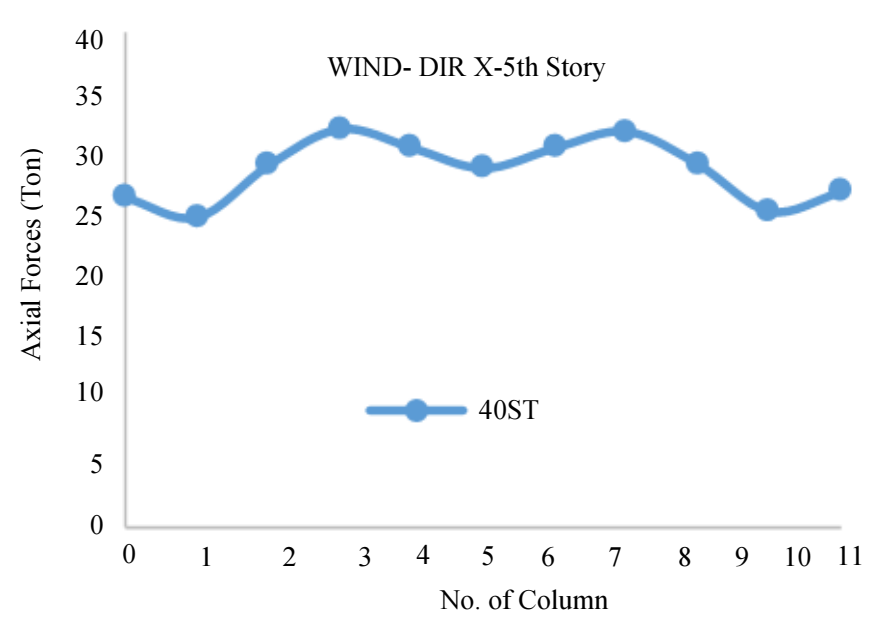

Fig. 6: The axial force of the columns in the 40th floor building on the 5th floor

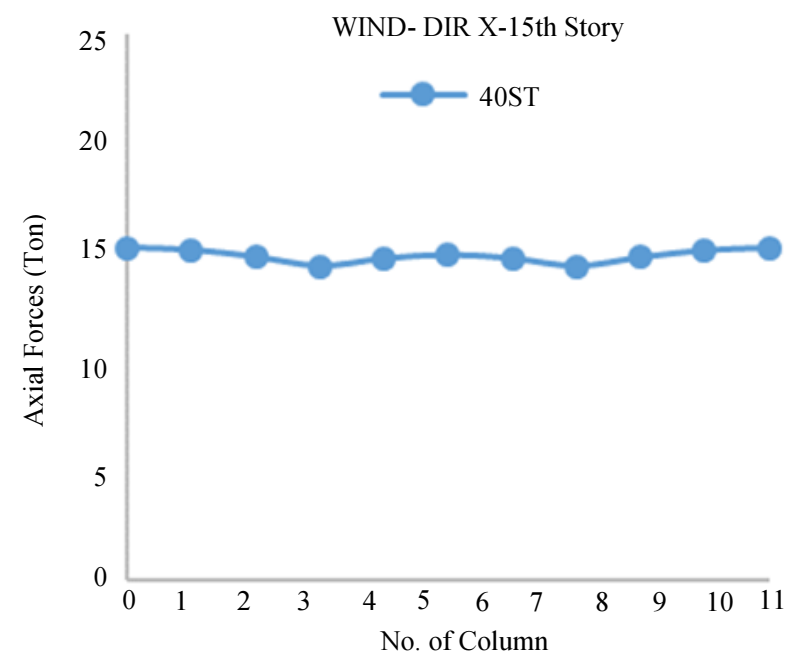

Fig. 7: The axial force of the columns in the 40th floor building on the 15th floor

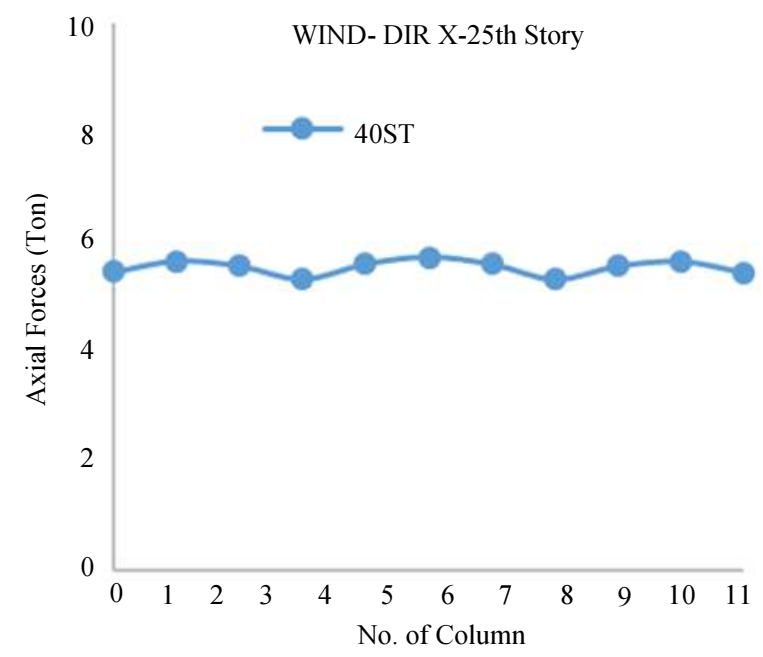

Fig. 8: The axial force of the columns in the 40th floor building on the 25 th floor 


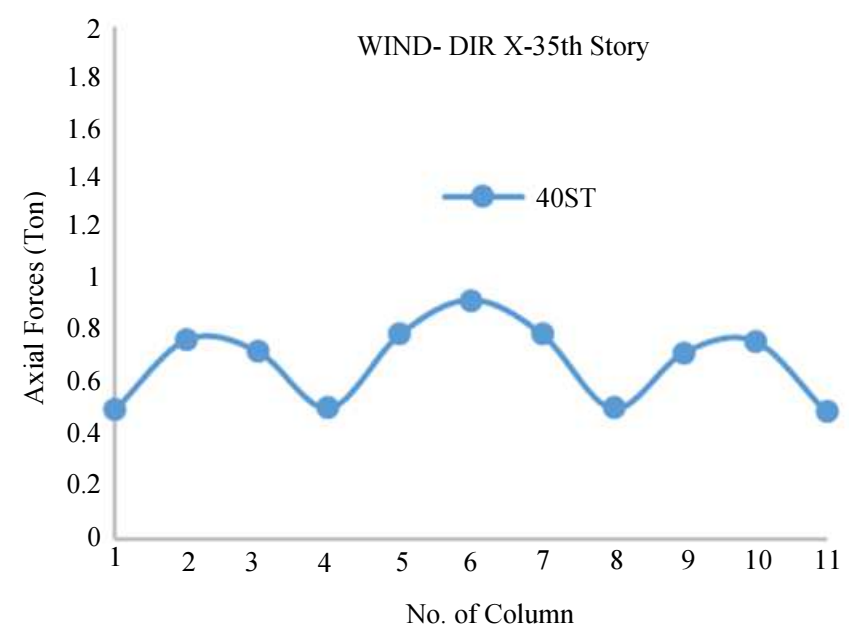

Fig. 9: The axial force of the columns in the 40th floor building on the 35th floor

In the following, the axial force of 11 columns is located on a perpendicular to the surface of the building's wind (located on the A-axis in Fig. 1 and without regarding to the two columns at the two ends). These columns will be shown on the A-axis from top to bottom with numbers 1 through 11 . In this study, the direction of $\mathrm{X}$ is considered. Figure 6 shows the axial force of these columns on the 5 th floor so that the range of axial force is between 25 and 35 tons. Figure 7 shows the axial force of the columns in the 15 th floor in which it has almost constant axial force about 15 tons for all indicated columns and also the Fig. 8 and 9 of the axial force of the columns in the 25 th and 35 th floors in which according to Fig. 9, the column number 6th has the maximum amount of axial load capacity.

According to the obtained forms, it is possible to obtain the shear lag factors in the 40-story building in different classes and compare the results. It should be noted in the building of 40 floors and on the 5th floor, the axial force of the middle columns at each span is less than the axial force of the columns of the corner. Given that the shear lag factor is defined as the axial force of the column to the middle of the corner, Table 4 can be provided. Regarding the values of the shear lag factor, the two states are distinguishable:

1) The shear lag factor is greater than a positive lag factor. In this case, the axial compressive strength of the corners is larger than the axial force of the middle columns

2) The shear lag factor is less than one, in which case the shear lag factor is negative. In this case, the axial force of the compression of the middle columns is larger than the axial force of the corner columns
Table 4: Shear lag factor of various spans of 40 floors

\begin{tabular}{lllll}
\hline Craters & 5th floor & 15th floor & 25th floor & 35th floor \\
\hline First span & 1.28 & 0.95 & 0.9 & 0.65 \\
Second span & 1.11 & 0.96 & 0.92 & 0.54 \\
Third span & 1.22 & 0.95 & 0.93 & 0.63 \\
Average & 1.2 & 0.95 & 0.92 & 0.61 \\
\hline
\end{tabular}

\section{Conclusion}

In this research, a 40-stories concrete building with a pipe system in a classified pipe is designed in accordance with ACI 318-11. The lateral load system is applied to the structure according to ASCE7-10. Under the lateral load, the shear lag factor is defined to determine the uniform distribution of the axial force of the columns in front of the wind and is calculated for different floors.

By examining the axial force results, the columns of 40-stories buildings are considered:

- In the lower floors of the building, the axial forces of the corners of the columns in each of the main spans are higher than the mid-columns

- In the higher elevation of the building, the factor of the shear lag was from the positive to the negative phase

- In the upper floors the axial force of the middle columns is more than the corners

- In the middle classes, the shear lag factor for an almost balanced distribution of the axial force of the corners and middle columns was about one

\section{Author's Contributions}

Reza Salehi: Performed modeling with ETABS software and data analysis. Also, participated in writing the manuscript. 
Abbas Akbarpour: Provided the research topic and guided the research development, experimental plan and data analysis. Also, participated in writing the manuscript.

\section{Ethics}

This article is an original research paper. There are no ethical issues that may arise after the publication of this manuscript.

\section{References}

Bagheri, M., 2012. Effect of shear lag phenomenon on high structures with tubular system and shear wall system and bracing under lateral load (wind) with regard to soil and structure interaction. M.Sc. Thesis, Shahid Madani University of Azarbaijan.

Fallahi, M., M. Haghighfar, R. Madandoust and S. Sayyar Roudsari, 2018. Modelling of reinforced concrete frames with Infill walls under cyclic loading Strengthening with CFRP. J. Eng. Applied Sci.

Khan, F.R., 1972. Influence of design criteria on selection of structural systems for tall buildings. Proceedings of the Canadian Structural Engineering Conference, (SEC' 72), Canadian Steel Industries Construction Council, Toronto, pp: 1-15.

Kheyroddin, A. and H. Jamshidi, 2008. Investigation of resistance systems of pipe structures in high-rise buildings. Proceedings of the National Rehabilitation Conference, (NRC' 08) Yazd.

Kheyroddin, A. and H. Naderpour, 2011. Investigation of the shear lag phenomenon in reinforced concrete buildings with tubular system. J. Model. Eng..

Kheyroddin, A. and S. Aramesh, 2013. Structural resistant systems in high buildings. Semnan University.
Moghadasi, M., 2009. Effect of adding internal tube(s) on behavior of framed tube tall buildings subjected to lateral load. Proceedings of the 7th Asian Pacific Structural Engineering and Construction Conference, (ECC' 09), Malaysia.

Moghaddasi, M. and A. Keramati, 2007. The effect of internal tubes on the behavior of long tube structures. Proceedings of the 5th International Conference on Seismology and Earthquake Engineering, (SEE' 07).

Paveloni, M., 2012. Future building systems: A look at future's architecture. Translation by Dr. Mahmoud Golabchi, Tehran University Publishers.

Roudsari, S., S. Hamoush, S. Soleimani, T.A. Lebdeh and M. Haghighi Far, 2018. Analytical study of reinforced concrete beams strengthened by FRP bars subjected to impact loading conditions. Am. J. Eng. Applied Sci. DOI: 10.3844/ofsp.11916

Sayyar Roudsari, S., S.A. Hamoush and S.M. Soleimani, Rahmat Madandoudst, 2018. Evaluation of largesize reinforced concrete columns strengthened for axial load using fiber reinforced polymers. Engineering Structure.

Smith, B.S. and A. Coull, 1991. Tall Building Structures: Analysis and Design. 1st Edn., John Wiley and Sons, New York, ISBN-10: 0471512370, pp: 537.

Soleimani, M. and S.S. Roudsari. 2015. Analytical study of reinforced concrete beams tested under impact loading. Proceedings of the 4th International Workshop Performance, Protection and Strengthening Structures Under Extreme Loading, (UEL' 15), pp: 620-627.

Taranath, B.S., 1982. Structural Analysis and Design of Tall Buildings. 1st Edn., Mc Graw-Hill, New York.

Tohidi, M., 1996. Investigation of shear lag in long pipe buildings and its reduction strategies. M.Sc. Thesis, Tehran University. 